CYSTIC FIBROSIS

\title{
Long term clinical outcome of home and hospital intravenous antibiotic treatment in adults with cystic fibrosis
}

\author{
J Thornton, R Elliott, M P Tully, M Dodd, A K Webb
}

Thorax 2004;59:242-246. doi: 10.1136/thx.2003.005876

See end of article for authors' affiliations

.....................

Correspondence to: Dr J Thornton, School of Pharmacy and Pharmaceutical Sciences, University of Manchester M13 9PL, UK; judith.thornton@man.ac.uk

Received 26February 2003 Accepted 14 November 2003
Background: Several studies have suggested that clinical outcomes in adults with cystic fibrosis (CF) are equivalent after home and hospital treatment with intravenous antibiotics, but these studies were small and selective and only considered one course of treatment.

Methods: A retrospective longitudinal study was performed to compare the clinical outcome over a period of 1 year of all patients attending the Manchester Adult CF Unit who received intravenous antibiotics at home or in hospital. The primary outcome measure was percentage change in forced expiratory volume in 1 second $\left(\mathrm{FEV}_{1}\right)$ at the end of the 1 year period. Baseline "best" and "average" FEV 1 values were established for each patient for the year before the study. The secondary outcome measures were percentage changes in forced vital capacity (FVC) and body weight.

Results: A total of 116 patients received 454 courses of intravenous antibiotics. At the end of 1 year there had been a mean percentage decline in $\mathrm{FEV}_{1}$ compared with the baseline "average" for patients treated mostly at home but an improvement in patients treated mostly in hospital (Tukey's HSD mean difference $10.1 \%, 95 \% \mathrm{Cl} 2.9$ to $17.2, \mathrm{p}=0.003$ ). For all patients there was a mean percentage decline in $\mathrm{FEV}_{1}$ from the baseline "best" value. For each course of treatment the mean percentage improvements in $F^{\prime} V_{1}$ at the end of the course from the start of the course were significantly higher for patients treated in hospital than for those treated at home.

Conclusions: Clinical outcome, as defined by spirometric parameters and body weight, was better after a course of treatment in hospital than after home treatment, and this benefit was maintained over 1 year of treatment. The results suggest that patients treated at home need closer supervision.
$\mathrm{P}$ atients with cystic fibrosis (CF) experience repeated infective respiratory exacerbations leading to a continued decline in lung function. ${ }^{1}$ The exacerbations are treated with courses of intravenous antibiotics which may be administered in hospital or at home. Home treatment for CF is well established in the $\mathrm{UK}_{,}{ }^{2}$ often driven by the lack of inpatient beds and the preference of patients. The cited advantages of home treatment are a reduced risk of cross infection, less time off work or school for patients, and improved quality of life. ${ }^{3}$ Twelve studies have compared home and hospital treatment in adults or children, ${ }^{2-14}$ but generally included only small numbers of patients and examined single courses of treatment with a limited range of antibiotic regimens, suggesting that the studies may not be representative of usual practice. A recent Cochrane Collaboration review of home and hospital treatment ${ }^{3}$ included only one randomised controlled trial ${ }^{6}$ and concluded that current evidence was too limited to draw conclusions for practice. A study to examine clinical outcome in patients after home and hospital treatment with intravenous antibiotics was therefore initiated. As patients receive repeated courses of treatment, the primary aim of the study was to compare outcome after 1 year.

\section{METHODS}

\section{Study population}

This retrospective, observational, l year pragmatic study was conducted in the Manchester Adult CF Centre, Wythenshawe Hospital, Manchester. Here the decision whether to treat at home or in hospital is made by the physician with the patient's agreement and the multidisciplinary team assesses patients for competency and likely adherence. All patients receiving intravenous antibiotics for a respiratory exacerbation were identified from the records of patients attending the centre between September 2000 and September 2001. The study recruited adults ( $\geqslant 16$ years) with a confirmed diagnosis of CF. Patients had to experience at least one respiratory exacerbation (defined as an increase in lower respiratory tract symptoms requiring treatment with intravenous antibiotics) during the 1 year study period. Patients were excluded if they received intravenous antibiotics for conditions other than respiratory exacerbations or if they received treatment at other hospitals (shared care). The data collected were patient demographics, microbiology, concomitant treatment, presence of diabetes, pregnancy, smoking, spirometric parameters, and body weight.

\section{Assessment of outcome}

The site of home or hospital treatment for each individual course of intravenous antibiotics was decided prospectively by the treating physician (AKW) with the agreement of the patient. Courses of intravenous antibiotics were categorised retrospectively by an independent investigator (JT) according to where the treatment started and regardless of any changes part way through the course. Thus, courses where treatment was started at home were categorised as home courses, and those where treatment started in hospital as hospital courses. Patients were then allocated retrospectively to treatment groups by the independent investigator according to where they received most treatment over the 1 year study period. Only a few patients received all of their treatment at home or in hospital over the 1 year study period, so "home" patients were those in whom the intention to treat had been home in $>60 \%$ of courses, "hospital" patients were those in whom the

Abbreviations: $\mathrm{BMI}$, body mass index; $\mathrm{FEV}_{1}$, forced expiratory volume in 1 second; FVC, forced vital capacity 
intention to treat had been hospital in $>60 \%$ of courses, and "both" patients were those in whom the intention to treat had been hospital or home in $40-60 \%$ of courses.

The primary clinical outcome variable was forced expiratory volume in 1 second $\left(\mathrm{FEV}_{1}\right)$. For home treatment, spirometric tests were performed at the start and end of each course of intravenous antibiotics. In hospital, spirometric testing was performed at admission, twice weekly, and at discharge. Two baseline $\mathrm{FEV}_{1}$ values were established in each patient for the baseline year before the 1 year study period. The "best" $\mathrm{FEV}_{1}$ was the highest $\mathrm{FEV}_{1}$ during the baseline year and the "average" $\mathrm{FEV}_{1}$ was the mean of all $\mathrm{FEV}_{1}$ values recorded during this period. The percentage predicted $\mathrm{FEV}_{1}$ was calculated for both values. ${ }^{15}$ Baseline forced vital capacity (FVC) and body weight values were also established and the percentage predicted FVC and body mass index (BMI, body weight in $\mathrm{kg} /$ height in $\mathrm{m}^{2}$ ) were calculated.

For each patient the final $\mathrm{FEV}_{1}, \mathrm{FVC}$, and body weight value were recorded as the last value of the last course at the end of the 1 year study period. The percentage changes in $\mathrm{FEV}_{1}, \mathrm{FVC}$, and body weight from baseline "best" to final and from baseline "average" to final were calculated. FEV, FVC, and body weight were determined for the start and end of each course of intravenous antibiotics. For each course the percentage changes from start to end were calculated.

Approval for the study was given by South Manchester local research ethics committee and patients were informed of the study by letter.

\section{Statistical analysis}

As the desired clinical outcome after treatment with intravenous antibiotics has not been quantified, it was not possible to perform power calculations to determine sample size. However, it was planned to recruit a cohort of 100 patients to the study and statistical advice confirmed that this number was sufficient when taking into account the aims of the study.

The differences between treatment groups at baseline were compared using independent sample $t$ tests for continuous variables and $\chi^{2}$ tests for nominal variables (SPSS version 11.5). Outcome was evaluated using analysis of variance (ANOVA) with interaction terms for potential confounding variables where appropriate. Multiple regression analysis was conducted to determine which patient characteristics might explain the decline in lung function (percentage decline in $\mathrm{FEV}_{1}$ from baseline "average" to the end of the l year study period). The following variables were entered into the model: site of treatment (expressed as percentage of courses of intravenous antibiotics administered in hospital), sex and age of patient, infection with Burkholderia cepacia, presence of diabetes, concomitant treatment with rhDNase, nebulised antibiotics or oral corticosteroids, baseline "average" percentage predicted $\mathrm{FEV}_{1}$, and baseline "average" BMI. The differences in outcome after one course of treatment were compared using independent samples $t$ tests.

\section{RESULTS}

\section{Patients and treatment}

Of a total clinic population of 220, 120 patients received treatment with intravenous antibiotics during the study period and 116 of these $(97 \%)$ were eligible for the study. Four patients were excluded for the following reasons: refused access to medical records, shared care, final $\mathrm{FEV}_{1}$ value missing, or clinical records missing (one patient each).

The 116 patients underwent treatment with 454 courses of intravenous antibiotics during the 1 year study period. The mean number of courses per patient was 4 (range 1-9). The mean and median course lengths were 15 and 14 days, respectively. A wide range of course lengths (3-172 days) was explained by some patients receiving almost continuous intravenous antibiotics. A total of 213 courses (46.9\%) were classified as home courses and 241 courses $(53.1 \%)$ as hospital courses. Forty seven patients $(40.5 \%)$ were allocated to "home", $51(44.0 \%)$ to "hospital", and $18(15.5 \%)$ to "both". Each group received similar amounts of intravenous antibiotic treatment during the study period (mean of 4, 3.6, and 4.5 courses in "home", "hospital" and "both" groups, respectively).

At baseline there were no statistically significant differences between the three treatment groups (tables 1 and 2) other than more female patients in the "home" treatment group than in the "hospital" treatment group $(\mathrm{p}=0.025)$.

\section{Outcome after 1 year}

All 116 patients were included in the analysis of outcome after 1 year. There was a mean percentage decline in $\mathrm{FEV}_{1}$ at the final value compared with the baseline "average" value. There was a mean percentage decline in the "home" group but a mean percentage improvement in the "both" and "hospital" groups $(\mathrm{F}=11.105, \mathrm{p}=0.001$; table 3$)$. The mean percentage improvement was significantly higher in the "hospital" group than in the "home" group $(p=0.003)$. FEV declined at the final measurement compared with baseline "best" for all patients and for the "home", "hospital", and "both" groups ( $\mathrm{F}=4.479, \mathrm{p}=0.037$; table 3$)$, and there was a trend towards a significant difference between the "home" and "hospital" groups $(\mathrm{p}=0.091)$.

Mean FVC improved compared with baseline "average" in "hospital" and "both" groups but declined in "home" patients $(\mathrm{F}=13.843, \mathrm{p}<0.001$; table 3$)$. The mean difference between "home" and "hospital" patients was statistically significant $(p=0.001)$. The mean percentage decline from baseline "best" FVC was greatest in "home" patients and least in "hospital" patients $(\mathrm{F}=5.182, \mathrm{p}=0.025)$, and there was a trend towards a significant difference between "home" and "hospital" treatment groups $(\mathrm{p}=0.063)$.

Body weight improved compared with baseline "average" in all treatment groups except in the "home" group $(\mathrm{F}=9.689, \mathrm{p}=0.002$; table 3$)$ and was significantly higher in the "hospital" patients than in the "home" patients. There was a mean percentage decline in body weight for all patients compared with the "best" values ( $\mathrm{F}=8.475, \mathrm{p}=0.004$; table 3); this was significantly less in the "hospital" treatment group than in the "home" treatment group.

At baseline the only difference between the patient groups was the distribution of male and female patients with significantly more women in the "home" treatment group than in the "hospital" treatment group. The results of the interaction analysis showed a significant interaction effect between the site of treatment and the sex of the patient on the percentage change in $\mathrm{FEV}_{1}$ from baseline "average" to final $(\mathrm{p}=0.002)$. There was a mean percentage improvement in $\mathrm{FEV}_{1}$ in hospital treated men $(8.2 \%, 95 \%$ CI 3.0 to 13.5$)$ but a mean decline in hospital treated women $(-1.4 \%, 95 \%$ CI -7.7 to 4.9$)$. The mean decline in home treated women $(-3.4 \%, 95 \%$ CI -8.7 to 1.9$)$ was less than for home treated men $(-10.0 \%, 95 \%$ CI -17.0 to -3.0$)$. There was no significant interaction effect on the percentage change in $\mathrm{FEV}_{1}$ from baseline "best" to the final value. Similar results were noted for FVC. For both body weight outcome measures there was a significant interaction effect between the site of treatment and the sex of the patients on outcome. For percentage change in body weight from baseline "average" to final in women there was a mean loss of weight at home $(-2.7 \%, 95 \%$ CI -5.5 to 0.1$)$ but a mean gain in hospital $(3.2 \%, 95 \%$ CI -0.2 to 6.6$)$. For men the mean changes in 


\begin{tabular}{|c|c|c|c|c|}
\hline & $\begin{array}{l}\text { All } \\
(N=116)\end{array}$ & $\begin{array}{l}\text { "Home" } \\
(\mathrm{N}=47)\end{array}$ & $\begin{array}{l}\text { "Hospital" } \\
(\mathrm{N}=51)\end{array}$ & $\begin{array}{l}\text { "Both" } \\
(N=18)\end{array}$ \\
\hline Mean (range) age (years) & $26(16-47)$ & $26(17-43)$ & $26(16-47)$ & $25(19-42)$ \\
\hline \multicolumn{4}{|l|}{ Infecting micro-organism (N (\%)) } & $61.1 / 38.9$ \\
\hline Pseudomonas aeruginosa & $103(88.9)$ & $43(91.5)$ & $42(82.4)$ & $18(100.0)$ \\
\hline Burkholderia cepacia & $18(15.5)$ & $6(12.8)$ & $9(17.6)$ & $3(16.7)$ \\
\hline Other Pseudomonas spp & $2(1.7)$ & 0 & $2(3.9)$ & 0 \\
\hline Staphylococcus aureus* ${ }^{\star}$ & 17 (14.7) & $8(17.0)$ & $7(13.7)$ & $2(11.1)$ \\
\hline Other & 51 (44.0) & $19(40.4)$ & $24(47.1)$ & $8(44.4)$ \\
\hline \multicolumn{5}{|l|}{ Concomitant treatment (N (\%)) } \\
\hline Nebulised rhDNase & 75 (64.7) & $30(63.8)$ & $32(62.7)$ & $13(72.2)$ \\
\hline Nebulised colistin & $58(50)$ & $26(55.3)$ & $21(41.2)$ & $11(61.1)$ \\
\hline Nebulised gentamicin & $9(7.8)$ & $6(12.8)$ & $2(3.9)$ & $1(5.6)$ \\
\hline Nebulised tobramycin & $2(1.7)$ & $2(4.3)$ & 0 & 0 \\
\hline Oral antibiotics & $104(89.7)$ & $43(91.5)$ & $45(88.2)$ & $16(88.9)$ \\
\hline Inhaled/nebulised corticosteroids & $109(94.0)$ & $45(95.7)$ & $48(94.1)$ & $16(88.9)$ \\
\hline Regular oral corticosteroids & $12(10.3)$ & $5(10.6)$ & $5(9.8)$ & $2(11.1)$ \\
\hline Inhaled/nebulised bronchodilators & $113(97.4)$ & 44 (93.6) & $51(100.0)$ & $18(100.0)$ \\
\hline Aminophylline, theophylline, salbutamol & $73(62.9)$ & $26(55.3)$ & $36(70.6)$ & $11(61.1)$ \\
\hline \multicolumn{5}{|l|}{ Diabetes (N (\%)) } \\
\hline Yes & $31(26.7)$ & $14(29.8)$ & 15 (29.4) & $2(11.1)$ \\
\hline Smoking (N (\%)) & $\mathrm{N}=101$ & $N=39$ & $N=47$ & $N=15$ \\
\hline $\begin{array}{l}\text { Yes } \\
\text { Pregnancy (N (\%)) }\end{array}$ & $\begin{array}{l}13(12.9) \\
N=56\end{array}$ & $\begin{array}{l}6(15.4) \\
N=29\end{array}$ & $\begin{array}{l}6(12.8) \\
N=21\end{array}$ & $\begin{array}{l}1(6.7) \\
N=6\end{array}$ \\
\hline Yes & $4(7.1)$ & $1(3.4)$ & $2(9.5)$ & $1(16.7)$ \\
\hline
\end{tabular}

body weight were $-1.9 \%$ (95\% CI -5.7 to 1.8 ) at home and $2.5 \%$ (95\% CI -0.8 to 4.9$)$ in hospital.

\section{Outcome after one course}

Out of 454 courses, start values were missing from 15 courses (3\%) where the patient was too ill to perform spirometric tests and end values were missing from 20 courses (4\%) where the patient did not return to the clinic after finishing a course of home treatment. The mean improvement in $\mathrm{FEV}_{1}$ from start to end of a course was significantly greater for hospital courses than for home courses $(p<0.001$; table 4$)$. Secondary outcome variables reflected the results for $\mathrm{FEV}_{\mathrm{l}}$ (table 4).

\section{Characteristics influencing outcome}

Regression analysis confirmed that only the site of treatment had an effect on the percentage change in $\mathrm{FEV}_{1}$ from baseline "average" to the end of the 1 year study period (coefficient $=0.09,95 \%$ CI 0.020 to $0.160, p=0.012$ ). Other baseline characteristics had no effect on outcome.

\section{DISCUSSION}

This study shows that clinical outcome was better after a course of intravenous antibiotics administered in hospital than after a course administered at home. The benefit of hospital treatment was maintained over 1 year.
The Cochrane Collaboration review of home and hospital treatment recommended initiation of randomised controlled trials to compare the two approaches, ${ }^{3}$ but randomised controlled trials may not be appropriate to evaluate all situations. ${ }^{16}$ Because of the variation in severity of disease and the number of antibiotic regimens used for treating respiratory infective exacerbations in $\mathrm{CF}$, a randomised controlled trial of home and hospital treatment may not reflect routine practice. Anecdotal evidence suggests that patients have strong preferences regarding site of treatment and refuse to be randomised, although it may be possible to build patient preferences into the trials. ${ }^{17}$ Furthermore, a randomised controlled trial may not be the best study design for patients with chronic or lifelong diseases such as CF as they rarely evaluate long term outcomes, ${ }^{18}$ and alternative study designs such as well conducted observational studies should be considered.

Lung function, particularly $\mathrm{FEV}_{1}$, is the most important objective clinical outcome measure in CF and it is expected that $\mathrm{FEV}_{1}$ will improve during a course of intravenous antibiotics. In practice, the main aim of treatment with intravenous antibiotics is to achieve and maintain the patient's best lung function. In this study both the highest and mean $\mathrm{FEV}_{1}$ values were recorded for the baseline year. The mean value possibly represented the patient's everyday condition more accurately than the highest value as the mean baseline "best" value was approximately $20 \%$ higher than the

Table 2 Mean (SD) "best" and "average" values for lung function, body weight, and body mass index (BMI) for the three treatment groups during the 1 year baseline period

\begin{tabular}{|c|c|c|c|c|c|c|}
\hline & \multicolumn{2}{|c|}{ "Home" ( $\mathrm{N}=47)$} & \multicolumn{2}{|c|}{ "Hospital" (N=51) } & \multicolumn{2}{|c|}{ "Both" (N= 18) } \\
\hline & "Best" & "Average" & "Best" & "Average" & "Best" & "Average" \\
\hline $\mathrm{FEV}_{1}$ (l) & $2.2(0.8)$ & $1.9(0.7)$ & $2.1(0.9)$ & $1.8(0.8)$ & $2.4(0.9)$ & $2.0(0.7)$ \\
\hline$\%$ predicted $\mathrm{FEV}_{1}$ & $64.7(22.4)$ & $54.8(19.0)$ & $59.3(22.1)$ & $49.3(18.6)$ & $60.6(19.1)$ & 50.4 (16.0) \\
\hline FVC (I) & $3.3(1.1)$ & $2.9(1.0)$ & $3.6(1.2)$ & $3.0(1.1)$ & $3.6(1.1)$ & $3.1(1.1)$ \\
\hline$\%$ predicted FVC & $82.6(21.4)$ & 72.4 (19.8) & $84.2(20.1)$ & 71.5 (19.7) & 78.7 (18.3) & 67.5 (16.3) \\
\hline Body weight $(\mathrm{kg})$ & $59.0(9.6)$ & 56.7 (9.1) & $60.0(12.5)$ & 57.7 (12.0) & $65.1(14.9)$ & 62.5 (14.6) \\
\hline $\mathrm{BMI}\left(\mathrm{kg} / \mathrm{m}^{2}\right)$ & $21.6(2.8)$ & $20.7(2.6)$ & $21.5(3.4)$ & $20.6(3.2)$ & $22.0(2.6)$ & $21.1(2.6)$ \\
\hline
\end{tabular}


Table 3 Mean (SD) percentage change from "best" and "average" values for lung function and body weight to end of 1 year study period

\begin{tabular}{|c|c|c|c|c|c|c|c|c|}
\hline & \multicolumn{2}{|l|}{ All $(\mathrm{N}=116)$} & \multicolumn{2}{|c|}{ “Home" (N=47) } & \multicolumn{2}{|c|}{ "Hospital" (N=51) } & \multicolumn{2}{|c|}{ "Both" (N= 18) } \\
\hline & "Best" & "Average" & "Best" & "Average" & "Best" & "Average" & "Best" & "Average" \\
\hline \multirow{3}{*}{$\begin{array}{l}\text { \% change to final } \\
\text { FEV } \\
\% \text { change to final } \\
\text { FVC } \\
\% \text { change to final } \\
\text { body weight }\end{array}$} & $-16.1(15.3)$ & $-0.3(15.5)$ & $-19.5(16.0)$ & $-5.8(15.0)^{\star}$ & $-13.0(15.7)$ & $4.3(16.4)^{*}$ & $-15.6(9.9)$ & $1.3(9.1)$ \\
\hline & $-11.8(14.6)$ & $2.2(13.5)$ & $-15.4(16.8)$ & $-3.0(15.1) \dagger$ & $-8.7(13.9)$ & $6.7(11.5) \dagger$ & $-10.9(6.6)$ & $3.1(9.1)$ \\
\hline & $-3.5(8.4)$ & $0.4(8.1)$ & $-6.2(8.9) \ddagger$ & $-2.4(8.5) \S$ & $-1.4(7.2) \ddagger$ & $2.5(7.0) \S$ & $-2.4(8.4)$ & $1.8(8.3)$ \\
\hline \multicolumn{9}{|c|}{$\begin{array}{l}\text { *Tukey's HSD mean difference } 10.1 \%(95 \% \mathrm{Cl} 2.9 \text { to } 17.2), \mathrm{p}=0.003 \text {. } \\
\text { †Tukey's HSD mean difference } 9.6 \%(95 \% \mathrm{Cl} 3.5 \text { to } 15.8), \mathrm{p}=0.001 \text {. } \\
\text { tTukey's HSD mean difference } 5.0 \%(95 \% \mathrm{Cl} 1.2 \text { to } 8.7), \mathrm{p}=0.007 \text {. } \\
\text { \$Tukey's HSD mean difference } 4.8 \%(95 \% \mathrm{Cl} 0.9 \text { to } 8.6), \mathrm{p}=0.012 \text {. }\end{array}$} \\
\hline
\end{tabular}

mean "average" value. Thus, the most useful clinical outcome after l year was the comparison with baseline "average" $\mathrm{FEV}_{\mathrm{l}}$. During our study the mean lung function improved between the start and end of one course of treatment. However, over 1 year there was a mean decline in lung function compared with baseline "average".

In $\mathrm{CF}$, inadequate caloric intake and/or malabsorption, increased energy loss, and increased energy expenditure are associated with pulmonary morbidity and mortality. ${ }^{19}$ There is a strong correlation between $\mathrm{FEV}_{1}$ and BMI and lung function may impinge on weight gain because of increasing energy expenditure for the work of breathing. ${ }^{20}{ }^{21}$ Lung infection and inflammation and treatment with antibiotics also increase energy expenditure. ${ }^{22}$ Patients with CF often lose weight when ill with a respiratory infection. In our study the changes in body weight reflected the changes in lung function.

An interesting finding in our study was the difference in outcome between male and female patients. It is interesting to speculate why outcome at home was better for women than for men; it is possible that women adhere better to home treatment. It is also noteworthy that there was a mean decline in $\mathrm{FEV}_{1}$ both at home and in hospital for women. It is recognised that survival for women with $\mathrm{CF}$ is less than that for men..$^{23}$ One explanation which may be worth investigating further is that women respond less well than men to intravenous antibiotic therapy.

Although our study assessed only clinical outcome, it would have been interesting to record health related quality of life (HRQoL). However, HRQoL cannot be assessed retrospectively. A validated instrument sensitive to home and hospital treatment was not available at the start of the study.

A criticism often directed at comparisons of home and hospital treatment is that hospital treated patients have more severe disease than home treated patients. In this study there was no difference in baseline patient characteristics, lung function, or body weight between the treatment groups and the regression analysis confirmed that the site of treatment was the only predictor of outcome. Some patients refused to be admitted to hospital for treatment even when very sick, and other patients who were less ill preferred hospital treatment for domestic reasons. Any possible bias in this study will be a result of the social and domestic circumstances of the patients.

Although most previous studies concluded that clinical outcome was at least equivalent after home and hospital treatment, three recent studies reported a significantly better improvement in lung function in hospital treated patients compared with home treated patients. ${ }^{7814}$ Hospital patients would be expected to fare better than home patients for a number of reasons. Patients in hospital receive closer management of their condition from the multidisciplinary team with intensive physiotherapy, greater dietetic input, and close supervision and monitoring of spirometry and body weight (table 5).

The usual antibiotic combination is a $\beta$-lactam with an aminoglycoside. Although patients receive the same intravenous antibiotics at the same total daily dose at home as in hospital, some regimens for home administration are adapted to make administration more convenient for patients at home or work, but this may reduce effectiveness of treatment. For example, $\beta$-lactam antibiotics are administered three or four times daily in hospital but only twice daily at home (although the total dose is adjusted to be the same as in hospital). Most home treated patients have totally implantable intravenous access systems fitted and, although some antibiotics are known to be more effective when administered by continuous infusion, home treated patients usually prefer to use bolus injections.

Considerable commitment is expected from patients, but they choose home treatment in order to maintain family, work and/or education commitments. Adherence by CF patients with treatment in general is recognised as being

Table 4 Mean (SD) percentage change in lung function and body weight from start to end of one course of treatment

\begin{tabular}{llll}
\hline & All courses & Home & Hospital \\
\hline \% change in FEV & $\mathrm{N}=423$ & $\mathrm{~N}=192$ & $\mathrm{~N}=231$ \\
Mean (SD) & $22.6(26.2)$ & $16.3(19.4)^{*}$ & $27.8(29.7)^{*}$ \\
\% change in FVC & $\mathrm{N}=415$ & $\mathrm{~N}=191$ & $\mathrm{~N}=224$ \\
Mean (SD) & $22.2(29.0)$ & $15.5(19.3) \dagger$ & $27.9(34.3) \dagger$ \\
\% change in body weight & $\mathrm{N}=385$ & $\mathrm{~N}=172$ & $\mathrm{~N}=213$ \\
Mean (SD) & $1.5(4.3)$ & $0.5(3.1) \ddagger$ & $2.4(4.9) \ddagger$ \\
\hline
\end{tabular}

${ }^{*}$ Mean difference $11.5 \%$ (95\% Cl 6.7 to 16.2), $\mathrm{p}<0.001$.

tMean difference $12.4 \%(95 \% \mathrm{Cl} 7.1$ to 17.7$), \mathrm{p}<0.001$.

tMean difference $1.9 \%(95 \% \mathrm{Cl} 1.1$ to 2.7$), \mathrm{p}<0.001$. 
Table 5 Comparison of home and hospital management of respiratory exacerbations

\begin{tabular}{|c|c|c|}
\hline & Hospital & Home \\
\hline Lung function & $\begin{array}{l}\text { Admission, twice weekly, } \\
\text { and discharge }\end{array}$ & Start and end of course \\
\hline Body weight & $\begin{array}{l}\text { Admission, twice weekly, } \\
\text { and discharge }\end{array}$ & Start and end of course \\
\hline Physiotherapy & Twice daily & $\begin{array}{l}\text { Self-performed } \\
\text { Assessment and advice } \\
\text { at beginning }\end{array}$ \\
\hline Nutritional input & Yes & No \\
\hline $\begin{array}{l}\text { Multidisciplinary } \\
\text { assessment }\end{array}$ & $\begin{array}{l}\text { Admission, twice weekly } \\
\text { and discharge }\end{array}$ & Start and end of course \\
\hline
\end{tabular}

poor and may potentially result in increased infective exacerbations leading to faster disease progression. ${ }^{24}$ Adherence may be worse in some patients undertaking home treatment. For example, although the competency of home treated patients to perform airway clearance is assessed, the level of adherence is not known. In several of the published studies which showed equivalent outcomes after home and hospital treatment, patients were carefully selected for home treatment $^{6911}$ suggesting that these patients were better motivated and more likely to adhere to treatment than routine practice. Furthermore, home treatment may be counterproductive; patients prefer it because they can continue with work and a normal life but this means that they are not resting and may not be receiving optimal treatment. The Manchester CF Centre does not recommend rest for patients at home because generally the patients are trying to fit home treatment around their lifestyle.

Finally, all patients managed by the Manchester CF Centre prepare and administer their intravenous antibiotics themselves and usually rely on family or friends for help in the first instance. The specialist CF nurses provide patient led support and patients receive home visits from the CF specialist nurses on request, but do not receive any other nursing support from the hospital or community. In fact, patients have declined physiotherapy support at home, stating that they do not know until the actual day whether they need help or not. Failing patency of venflons is a frequent problem at home resulting in missed doses; patients are instructed to visit the nearest outpatient department for replacement.

There are a number of possible explanations as to why most previous studies have identified no difference in outcome. Our study included many more patients and courses of treatment than previous studies. The pragmatic design meant that patients were eligible who would have been excluded from previous studies. In addition, the study included all currently used drugs and doses and was not limited to certain antibiotic regimens.

Treating all patients in hospital is not possible because of insufficient numbers of beds and the preference of patients. Closer supervision of home treatment and physiotherapy may be needed to identify problems and increase adherence to treatment. Commercial homecare companies can supply a package of care including delivery of ready prepared infusion solutions, general and nursing support, and may offer an answer. However, these approaches to improve support for home treated patients have resource implications for hospitals and the health service.

In conclusion, the present study shows that, after treatment with intravenous antibiotics for infective respiratory exacerbations in patients with $\mathrm{CF}$, the long term clinical outcome is better in patients treated in hospital than in those treated at home. As it is impossible to treat all patients in hospital, these findings suggest that more intensive supervision at home may be needed.

\section{ACKNOWLEDGEMENTS}

The authors acknowledge the help of the multidisciplinary team, Manchester Adult Cystic Fibrosis Centre, Wythenshawe Hospital.

\section{Authors' affiliations}

J Thornton, R Elliott, M P Tully, School of Pharmacy and Pharmaceutical Sciences, University of Manchester M13 9PL, UK

M Dodd, A K Webb, Manchester Adult Cystic Fibrosis Centre, Wythenshawe Hospital, Manchester M23 9LT, UK

The study was funded by the School of Pharmacy and Pharmaceutical Sciences, University of Manchester.

\section{REFERENCES}

1 Packe G, Hodson M. Changes in spirometry during consecutive admissions for infective exacerbations in adolescent and adult cystic fibrosis. Respir Med 1992;86:45-8.

2 Pond $M$, Newport $M$, Joanes $D$, et al. Home versus hospital intravenous antibiotic therapy in the treatment of young adults with cystic fibrosis. Eur Respir J 1995;7:1640-4.

3 Marco T, Asensio O, Bosque M, et al. Home intravenous antibiotics for cystic fibrosis (Cochrane Review). Issue 1. In: The Cochrane Library. Oxford, Update Software, 2001.

4 Winter R, George R, Deacock S, et al. Self-administered home intravenous antibiotic therapy in bronchiectasis and adult cystic fibrosis. Lancet 1984;1:1338-9.

5 Martinez M, Votrubek W, Hoefler K, et al. Efficacy of respiratory home care versus inpatient care for cystic fibrosis patients. Am Rev Respir Dis 1987; 135:A194.

6 Wolter J, Bowler S, Nolan P, et al. Home intravenous therapy in cystic fibrosis: a prospective randomized trial examining clinical, quality of life and cost aspects. Eur Respir J 1997; 10:896-900.

7 Bradley J, Wallace E, Elborn J, et al. An audit of the effect of intravenous antibiotic treatment on spirometric measures of pulmonary function in cystic fibrosis. Ir J Med Sci 1999;168:25-8.

8 Esmond G, Butler M, McCormack A, et al. Comparison of hospital and home intravenous antibiotic therapy in adults with cystic fibrosis. J Cystic Fibrosis 2002; 1(Suppl 1):P362.

9 Donati MA, Guenette G, Auerbach H. Prospective controlled study of home and hospital therapy of cystic fibrosis pulmonary disease. J Pediatr 1987; 111:28-33.

10 Gilbert J, Robinson T, Littlewood J. Home intravenous antibiotic treatment in cystic fibrosis. Arch Dis Child 1988;63:512-7.

11 Davis S, Mather F, Tankersly P, et al. A randomized trial of home intravenous antibiotic therapy in cystic fibrosis: short-term safety and efficacy. Pediatr Pulmonol 1990; (Suppl 5):A207.

12 Strandvik B, Hielte L, Malmborg A-S, et al. Home intravenous antibiotic treatment of patients with cystic fibrosis. Acta Paediatr 1992;81:340-4.

13 Van der Laag J, van de weg L. Cystic fibrosis and outpatient treatment with parenteral antibiotics in children. Int J Antimicrob Ag 1995;5:63-5.

14 Bosworth DG, Nielson DW. Effectiveness of home versus hospital care in the routine treatment of cystic fibrosis. Pediatr Pulmonol 1997;24:42-7.

15 Knudson R, Lebowitz M, Holberg C, et al. Changes in the normal maximal expiratory flow-volume curve with growth and aging. Am Rev Respir Dis 1983; 127:725-34

16 Black $N$. Why do we need observational studies to evaluate the effectiveness of health care? BMJ 1996;312:1215-8.

17 Torgerson DJ, Sibbald B. What is a patient preference trial? BMJ 1998:316:360.

18 Elphick HE, Tan A, Ashby D, et al. Systematic reviews and lifelong diseases. BMJ 2002;325:381-4.

19 Corey M, McLaughlin F, Williams M, et al. A comparison of survival, growth and pulmonary function in patients with cystic fibrosis in Boston and Toronto. J Clin Epidemiol 1988;41:583-91.

20 Bell S, Saunders M, Elborn J, et al. Resting energy expenditure and oxygen cost of breathing in patients with cystic fibrosis. Thorax 1996:51:126-31.

$21 \operatorname{Amin}$ N, Dozor A. Effects of administration of aerosolised recombinant human deoxyribonuclease on resting energy expenditure in patients with cystic fibrosis. Pediatr Pulmonol 1994;18:150-4.

22 MacDonald A. Nutritional management of cystic fibrosis. Arch Dis Child 1996;74:81-7.

23 Rosenfeld M, Davis R, FitzSimmons S, et al. Gender gap in cystic fibrosis mortality. Am J Clin Epidemiol 1997; 145:794-803.

24 Dodd ME, Webb AK. Understanding non-compliance with treatment in adults with cystic fibrosis. J R Soc Med 2000;93(Suppl 38):2-38. 